\title{
Influência da fermentação na qualidade da farinha de mandioca do grupo d'água
}

\begin{abstract}
Renan Campos CHISTÉ ${ }^{1}$, Kelly de Oliveira COHEN ${ }^{2}$
RESUMO

A etapa de fermentação na produção da farinha de mandioca do grupo d'água é responsável pelo desenvolvimento de características químicas e sensoriais peculiares no produto. O objetivo deste estudo foi verificar a influência da etapa de fermentação das raízes de mandioca nos principais parâmetros físico-químicos da farinha, seguido de avaliaçáo sensorial da preferência do consumidor. As análises realizadas foram determinação do teor de umidade, cinzas, proteínas, amido e acidez total titulável. O teste sensorial utilizado foi o de ordenaçáo-preferência dos produtos. De acordo com os resultados obtidos, a etapa de fermentação, responsável pelo aumento da acidez total titulável da farinha de mandioca do grupo d'água, foi o único parâmetro que excedeu o valor limite permitido pela legislaçáo brasileira vigente. Com base no resultado da análise sensorial, houve maior preferência dos consumidores pela farinha de mandioca com maior teor de acidez total $\left(3,44 \mathrm{cmol} \mathrm{NaOH} \mathrm{kg}^{-1}\right)$, que corresponde à raiz fermentada por 96 horas.
\end{abstract}

PALAVRAS-CHAVE: acidez, mandioca, processamento, análise sensorial.

\section{Influence of fermentation on the quality of fermented cassava flour}

\section{ABSTRACT}

The fermentation stage in the production of fermented cassava flour (also known as farinha d'água in Brazil) is responsible for the development of chemical and sensorial characteristics in the product. Thus the aim of this study was to verify the influence of the fermentation stage in the flour's main physicochemical parameters, followed by sensory evaluation of customer preference. The analyses performed were moisture, ash, protein, starch amounts and total acidity. The sensory analysis of the produced flour was performed using the preference-ordering test. According to the results, the fermentation stage, responsible for the increase of total acidity content in the final product, was the only parameter which exceeds the value demanded by Brazilian legislation. Based on the result of sensorial analysis, most customers preferred cassava flour with the highest amount of total acidity $\left(3.44 \mathrm{cmol} \mathrm{NaOH} \mathrm{kg}^{-1}\right)$, which correspond to the root fermented for 96 hours.

KEYWORDS: acidity, cassava, processing, sensorial analysis. 


\section{INTRODUÇÃO}

A mandioca (Manihot esculenta Crantz) é uma raiz com alto teor de amido e tem sido cultivada na América Tropical há mais de 5000 anos. É originária da Amazônia brasileira, região fronteiriça com a Venezuela e constitui-se em alimento energético para mais de 400 milhóes de pessoas no mundo, sobretudo nos países em desenvolvimento (Cagnon et al. 2002).

O Brasil figura como um dos maiores produtores dessa espécie e também como grande consumidor. De acordo com o IBGE (2008), no Brasil a área colhida na safra de 2007 foi de 1.926.332 hectares, com produçáo de 26.803 .655 toneladas. A maioria da produção brasileira de mandioca é destinada à produção de farinha de mandioca, sendo o Brasil o único país da América Latina que consome farinha em quantidades expressivas (Vilpoux 2003).

No estado do Pará, a mandioca, como principal fonte de carboidrato para uma significativa parcela da população, tem importância econômica para os municípios produtores e para o Estado, por meio da comercialização da farinha (Chisté et al. 2007). De acordo com Cereda e Vilpoux (2003), o consumo per capita anual de farinha de mandioca na região metropolitana de Belém é de $34 \mathrm{~kg}$, sendo o mais alto do Brasil e 2,35 vezes maior que o consumo da região metropolitana de Salvador, que é o segundo maior consumidor deste produto no país.

A farinha d'água é um produto específico da região Amazônica, mas consumida até o estado do Maranhão. É uma farinha fermentada e possui granulação bem maior em relação às outras farinhas (Vilpoux 2003). Segundo a Portaria no 554, de 30 de agosto de 1995 do Ministério da Agricultura Pecuária e Abastecimento - MAPA (Brasil 1995), a farinha de mandioca d'água é "o produto das raízes de mandioca sadias, devidamente limpas, maceradas (fermentadas), descascadas, trituradas, prensadas, desmembradas, peneiradas, secas à temperatura moderada, podendo novamente ser peneiradas ou não”.

A fermentação consiste no amolecimento das raízes de mandioca durante o processo fermentativo, e é realizada em água parada ou corrente (igarapés), a qual confere às raízes características sensoriais peculiares (Cereda e Vilpoux 2003). De acordo com Maravalhas (1964) o sabor e odor da farinha d'água são determinados pela maceração, sendo a principal fermentação provavelmente a butírica por Clostridium sp. devido ao acentuado odor butírico exalado.

Chisté et al. (2007) reportam que a etapa de fermentação da raiz de mandioca contribui para que a qualidade da farinha d'água não esteja dentro dos padróes exigidos pela legislação Brasileira, de acordo com a Portaria no 554 de 30/08/1995 do MAPA (Brasil 1995). Portanto, o objetivo deste estudo é avaliar a influência da etapa de fermentação da raiz de mandioca sobre os constituintes físico-químicos da farinha, como fator de alteração da qualidade, assim como a aceitaçáo sensorial do produto.

\section{MATERIAL E MÉTODOS}

\section{Matéria-prima}

As raízes de mandioca utilizadas no processamento da farinha foram da cultivar Maranhense II, com 12 meses de cultivo, polpa de coloração amarelada, indicada para utilização pelo setor de agroindústria. As amostras foram obtidas no Banco de Germoplasma da Embrapa Amazônia Oriental, Belém, Pará, Brasil.

\section{Produção da farinha de mandioca do grupo d'água}

Após recepção da matéria-prima, as raízes de mandioca foram submetidas à etapa de fermentação (maceração) por um período de 4 dias em tanques artesanais com água parada em quantidade suficiente para que a mandioca ficasse totalmente submersa (procedimento realizado de acordo com o adotado em casas de farinha do interior do Pará). Transcorrido o período de fermentação, as raízes apresentavam aspecto amolecido contribuindo para a fácil remoção da casca. Após a retirada das cascas, as raízes foram trituradas em processador de alimentos caseiro, prensadas em prensa hidráulica (modelo 60 ton., Skay, São José do Rio Preto, São Paulo) para remoção da manipueira, e finalmente encaminhada para a etapa de torração em tacho de cobre. A temperatura média do forno parra torração da farinha era $160 \pm 10^{\circ} \mathrm{C}$, com tempo de residência da massa triturada e prensada de cinco minutos, sob agitação constante.

\section{Determinação dos constituintes físico-químicos}

Para determinação dos constituintes físico-químicos foram analisados: mandioca descascada não-fermentada, mandioca descascada após 24, 48, 72 e 96 horas de fermentação e a farinha de mandioca produzida a partir dos diferentes tempos de fermentação da raiz. As análises do teor de umidade (\%), cinzas (\%), acidez total titulável $\left(\mathrm{cmol} \mathrm{NaOH} . \mathrm{kg}^{-1}\right)$ e proteínas (\%, utilizando 6,25 como fator de conversão do nitrogênio total) foram realizadas de acordo com a AOAC (1997). O teor de amido (\%) foi determinado pela metodologia de hidrólise ácida em microondas (Cereda et al. 2004). Todas as análises foram realizadas em triplicata.

\section{Análise sensorial da farinha de mandioca d'água}

Foi aplicado o teste de ordenação-preferência nos produtos, de acordo com procedimento descrito por Dutcoksky (1996), para avaliar a preferência dos consumidores com relação ao atributo sabor, influenciado pelo tempo de maceraçáo da raiz de mandioca para produção da farinha 
d'água. Participaram do teste 60 provadores não-treinados e quatro amostras diferentes de farinha d'água com distintos teores de acidez total, codificadas com números de três dígitos. Para a análise dos resultados foi utilizado o Teste de Friedman (Dutcoksky 1996), que indica a diferença crítica entre os totais de ordenaçáo, de acordo com o número de tratamentos testados e o número de julgamentos obtidos em nível de 5\% de significância. Dessa forma, para quatro tratamentos e 60 julgadores, a diferença crítica entre os totais de ordenação a 5\% de significância é de 37.

\section{Análise estatística dos resultados}

Os resultados obtidos durante o estudo no que se refere às determinaçôes físico-químicas (média \pm desvio padrão) foram avaliados empregando-se a análise de variância (ANOVA) e o Teste de Tukey $(\mathrm{p} \leq 0,05)$ utilizando o software Statistica for Windows 5.5 (Statsoft 2000).

\section{RESULTADOS E DISCUSSÃO}

Os teores de acidez total foram diferentes estatisticamente em todos os períodos analisados (Tabela 1). As raízes de mandioca, antes da etapa de fermentação, apresentaram acidez de $1,37 \mathrm{cmol} \mathrm{NaOH} \cdot \mathrm{kg}^{-1}$. A acidez das raízes apresentou decréscimo até 48 horas do processo fermentativo em função da diluiçấo dos ácidos na água contida no tanque de fermentação. Após esse período, a acidez total aumentou para $1,56 \mathrm{cmol} \mathrm{NaOH} \cdot \mathrm{kg}^{-1}$ no tempo correspondente a 96 horas de fermentação. A elevação de acidez entre os períodos de 48 e 72 horas sugere o início do processo fermentativo ocorrendo na matéria-prima, conforme relatado por Chisté et al. (2007).

Antes do processo de maceração, as raízes de mandioca apresentavam 26,8\% de amido. Este teor está abaixo do que Cagnon et al. (2002) citam para raízes de mandioca, que pode variar de 30-35\%, dependendo da cultivar. As raízes tenderam a apresentar decréscimos nos teores de amido durante o processo fermentativo. Neste processo o amido, principal carboidrato presente na raiz, é utilizado para produção de açúcares e ácidos orgânicos diversos, ocasionando aumento na acidez total. Parte do amido presente na raiz também é carreada para a água e por fim, é decantado no fundo do tanque, conforme observação experimental. Comportamento
Tabela 1 - Acidez total e teor de amido durante as etapas de fermentação da mandioca.

\begin{tabular}{ccc}
\hline $\begin{array}{c}\text { Tempo de fermentação } \\
(\mathrm{h})\end{array}$ & $\begin{array}{c}\text { Acidez total titulável } \\
\left(\mathrm{cmol} \mathrm{NaOH} \cdot \mathrm{kg}^{-1}\right)^{*}\end{array}$ & $\begin{array}{c}\text { Amido } \\
(\%)^{*}\end{array}$ \\
\hline 0 & ${ }^{\mathrm{c}} 1,37 \pm 0,02$ & ${ }^{\mathrm{a}} 26,84 \pm 0,10$ \\
24 & ${ }^{\mathrm{d}} 0,66 \pm 0,01$ & ${ }^{\mathrm{b}} 22,03 \pm 0,01$ \\
48 & ${ }^{\mathrm{e}} 0,36 \pm 0,01$ & ${ }^{\mathrm{c}} 20,42 \pm 0,01$ \\
72 & ${ }^{\mathrm{b}} 1,48 \pm 0,01$ & ${ }^{\mathrm{c}} 20,67 \pm 0,06$ \\
96 & ${ }^{\mathrm{a}} 1,56 \pm 0,05$ & ${ }^{\mathrm{d}} 19,26 \pm 0,05$ \\
\hline
\end{tabular}

*valores expressos em base úmida. $\mathrm{cmol} \mathrm{NaOH} \cdot \mathrm{kg}^{-1}=$ centimol de hidróxido de sódio por quilo. Médias com letras iguais, em uma mesma coluna, não diferem significativamente entre si (Teste de Tukey a 5\% de significância). Média de três medições \pm desvio padrão.

semelhante foi encontrado por Chisté e Cohen (2007) na produção da farinha de mandioca do grupo seca ao deixarem a massa de raiz triturada em repouso por 24 horas, sob temperatura ambiente, verificando aumento na acidez total e diminuiçáo no teor de amido durante o processamento.

Com relação à acidez total, as farinhas produzidas a partir de 72 horas de maceração apresentam valores de acidez total titulável acima do permitido pela legislaçáo brasileira $(3 \mathrm{cmol}$ $\mathrm{NaOH} . \mathrm{kg}^{-1}$ ) (Tabela 2). Chisté et al. (2007) verificaram que a acidez total das farinhas d'água, produzidas em casas de farinha no interior do Pará, variavam na faixa de 6,54 a 10,19 cmol $\mathrm{NaOH} . \mathrm{kg}^{-1}$, valores superiores aos encontrados neste estudo. Dias e Leonel (2006) e Chisté et al. (2006) ao avaliarem diferentes farinhas de mandioca, também encontraram valores superiores ao permitido pela legislação vigente.

Os valores de umidade das farinhas produzidas variaram de 3,86 a 9,20\%, e tal variação pode ser explicada devido aos fatores que influenciam o processo de torração do produto, como tempo de torraçáo, temperatura do forno, eficiência do processo de prensagem, entre outros. Chisté et al. (2007) encontraram valores de umidade inferiores que variaram de 1,43 a $2,12 \%$ para a farinha d'água; e Dias e Leonel (2006) encontraram valores semelhantes variando de 3,10 a $11,57 \%$. Em todos os casos, as amostras encontram-se dentro dos padróes exigidos pela Portaria no 554 de 30/08/1995 do MAPA (Brasil 1995), cujo máximo permitido é de 13\%.

Os teores de cinzas encontrados nas amostras de farinha de mandioca, independente do tempo de fermentação das

Tabela 2 - Características físico-químicas das farinhas d'água produzidas a partir de raízes de mandioca com diferentes tempos de fermentação.

\begin{tabular}{cccccc}
\hline $\begin{array}{c}\text { Tempo de Fermentação } \\
(\mathrm{h})\end{array}$ & $\begin{array}{c}\text { Acidez total titulável } \\
\left(\mathrm{cmol} \mathrm{NaOH} \cdot \mathrm{kg}^{-1}\right)^{*}\end{array}$ & $\begin{array}{c}\text { Umidade } \\
(\%)\end{array}$ & $\begin{array}{c}\text { Cinzas } \\
(\%)^{*}\end{array}$ & $\begin{array}{c}\text { Proteínas } \\
(\%)^{*}\end{array}$ & $\begin{array}{c}\text { Amido } \\
(\%)^{*}\end{array}$ \\
\hline 24 & ${ }^{\mathrm{b}} 1,90 \pm 0,01$ & ${ }^{\mathrm{a}} \mathrm{a}, 20 \pm 0,28$ & ${ }^{\mathrm{a}} 0,72 \pm 0,01$ & ${ }^{\mathrm{a}} 2,16 \pm 0,16$ & ${ }^{\mathrm{c}} 70,20 \pm 0,01$ \\
48 & ${ }^{\mathrm{c}} 0,86 \pm 0,03$ & ${ }^{\mathrm{b}} 5,57 \pm 1,34$ & ${ }^{\mathrm{c}} 0,50 \pm 0,02$ & ${ }^{\mathrm{b}} 1,62 \pm 0,16$ & ${ }^{\mathrm{b}} 71,49 \pm 0,04$ \\
72 & ${ }^{\mathrm{a}} 3,34 \pm 0,12$ & ${ }^{\mathrm{b}} 4,19 \pm 0,06$ & ${ }^{\mathrm{b}} 0,53 \pm 0,01$ & ${ }^{\mathrm{b}} 1,60 \pm 0,14$ & ${ }^{\mathrm{c}} 70,27 \pm 0,02$ \\
96 & ${ }^{\mathrm{a}} 3,44 \pm 0,10$ & ${ }^{\mathrm{b}} 3,86 \pm 0,16$ & ${ }^{\mathrm{b}} 0,54 \pm 0,01$ & ${ }^{\mathrm{b}} 1,57 \pm 0,13$ & ${ }^{\mathrm{a}} 75,01 \pm 0,01$ \\
\hline
\end{tabular}

*valores expressos em base úmida. $\mathrm{cmol} \mathrm{NaOH} . \mathrm{kg}^{-1}=$ centimol de hidróxido de sódio por quilo. Médias com letras iguais, em uma mesma coluna, não diferem significativamente entre si (Teste de Tukey a $5 \%$ de significância). Média de três medições \pm desvio padrão. 
raízes, estấo abaixo do permitido pela legislaçáo vigente, que é no máximo 1,5\% (Brasil 1995). Segundo Cagnon et al. (2002) os valores de cinzas estão relacionados com a cultivar de mandioca, assim como suas características de solo e cultivo.

De acordo com a Portaria no 554 de 30/08/1995 do MAPA, não há referências com relação aos valores de proteínas da farinha de mandioca. Entretanto, neste estudo, foi realizada tal determinação como informação complementar referente aos constituintes do produto. Foi observado que a farinha de mandioca não se trata de um produto com elevados teores de proteínas. Os valores encontrados no presente trabalho $(1,57$ a 2,16 \%) foram maiores do que os encontrados por Dias e Leonel (2006) em diversos tipos de farinha de mandioca $(0,57$ a $1,06 \%)$, Chisté et al. (2006) em farinha seca $(0,59$ a $0,93 \%)$ e Chisté et al. (2007) em farinha d'água (0,76 a 0,94\%).

Para a farinha de mandioca do grupo d'água é exigido teor mínimo de 70\% de amido (Brasil 1995). Todas as farinhas produzidas após diferentes tempos de maceração da raiz apresentaram valores dentro do permitido pela legislaçáo, variando de 70,20 a 75,01\%. Chisté et al. (2007) após avaliação do processo artesanal de fabricação da farinha d'água no interior do Pará, também encontraram valores dentro do limite mínimo permitido pela legislaçáo.

De acordo com os resultados do teste de ordenaçãopreferência (Tabela 3) realizado nas diferentes amostras de farinha d'água, com distintos valores de acidez total, foi verificado que a amostra de farinha produzida após 48 horas de maceração da raíz de mandioca (menor acidez total) apresentou a menor pontuação de preferência, diferindo significativamente somente da amostra produzida após 96 horas de maceração. As farinhas produzidas após 24 e 72 horas de meceração da mandioca apresentaram preferência intermediária em relação às outras, não diferindo significativamente das demais amostras. Finalmente a farinha produzida após 96 horas de maceraçáo da mandioca (maior acidez total) apresentou maior pontuação em preferência, diferindo apenas da amostra com 48 horas de maceração.

A preferência pela farinha com sabor mais ácido pode estar relacionada com hábitos culturais dos consumidores desse tipo

Tabela 3 - Teste de ordenação-preferência realizado nas diferentes farinhas d'água produzidas com diferentes tempos de fermentação.

Tempo de fermentação

(h)

$\begin{array}{ll}48 & { }^{b} 124 \\ 24 & { }^{a b} 152 \\ 72 & { }^{a b} 154 \\ 96 & { }^{a} 170\end{array}$

Participaram do teste 60 provadores não-treinados. Médias com letras iguais, em uma mesma coluna, não diferem significativamente entre si (Teste de Friedman a $5 \%$ de significância). de produto diferenciado, que optam por adquirir a farinha d'água por apresentar o referido sabor "mais ácido", resultante do tempo de fermentação superior a 48 horas.

\section{CONCLUSÕES}

A etapa de maceração da raiz de mandioca é responsável pelo elevado teor de acidez total na farinha d'água, dificultando assim o enquadramento do produto ao parâmetro exigido pela legislação vigente. No entanto, o teste sensorial de ordenaçãopreferência indica que os provadores possuem preferência pelo sabor da farinha de mandioca do grupo d'água com maior acidez total.

Portanto, sugere-se que este valor seja melhor avaliado pelos órgãos competentes com a finalidade de facilitar o enquadramento da farinha d'água nas condiçôes de qualidade especificadas pela legislação.

\section{AGRADECIMENTOS}

Ao CNPq (Conselho Nacional de Desenvolvimento Científico e Tecnológico) e ao Fundo Estadual de Ciência e Tecnologia (FUNTEC) / Secretaria Executiva de Ciência, Tecnologia e Meio Ambiente (SECTAM), pelo apoio financeiro.

\section{BIBLIOGRAFIA CITADA}

AOAC. 1997. Official methods of analysis of the Association of Official Analytical Chemists. V.2, Edited Ig W. Horwitz, 16a ed., Washington, DC, USA. 850 pp.

Brasil. 1995. Ordinance $n^{\circ} 554$ of August 30, 1995 (Portaria $n^{\circ} 554$ de 30 de agosto de 1995). Diário Oficial. Brasília, Secretaria da Agricultura, do Abastecimento e Reforma Agrária. 1 Set., Seção 1 (in Portuguese).

Cagnon, J.R.; Cereda, M. P.; Pantarotto, S. 2002. Culture of starchy tubers in Latin America. Volume 2: Culture of starchy tubers in Latin-America, Fundação Cargill, São Paulo, SP, Brasil. 537 pp (in Portuguese).

Cereda, M.P.; Daiuto, E.R.; Vilpoux, O. 2004. Methodology for determination of starch by acid digestion in microwave. Revista da Associação Brasileira dos Produtores de Amido de Mandioca (ABAM), ano II, n.8, p.29 (in Portuguese, with abstract in English).

Cereda, M.P.; Vilpoux, O.F. 2003. Culture of starchy tubers in Latin America. Volume 3: Technology, use and potentialities of LatinAmerican starchy tubers, Fundação Cargill, São Paulo, SP, Brasil. 694 pp (in Portuguese).

Chisté, R.C.; Cohen, K.O. 2007. Total acidity and starch behavior in the cassava flour production of dry group. Revista Brasileira de Tecnologia Agroindustrial, 1: 17-25 (in Portuguese, with abstract in English).

Chisté, R.C.; Cohen, K.O.; Mathias, E.A.; Ramôa Jr, A.G.A. 2007. Study of physical-chemical and microbiological properties when processing cassava flour from the water group. Ciência 
e Tecnologia de Alimentos, 27: 265-269 (in Portuguese, with abstract in English).

Chisté, R.C.; Cohen, K.O.; Mathias, E.A.; Ramôa Jr, A.G.A. 2006. Quality of cassava flour from a dry group. Ciência e Tecnologia de Alimentos, 26: 861-864 (in Portuguese, with abstract in English).

Dias, L.T.; Leonel, M. 2006. Phisico-chemical characteristics of cassava flours from different regions of Brazil. Ciência e Agrotecnologia, 30: 692-700 (in Portuguese, with abstract in English).

Dutcoksky, S. D. 1996. Sensory analysis offoods. Editora Champagnat, Curitiba, PR, Brasil, 123 pp (in Portuguese).

IBGE. 2008. Instituto Brasileiro de Geografia e Estatística - Systematic survey of agricultural production. Available at: (http://www.ibge. gov.br/home/estatistica/indicadores/agropecuaria/lspa/default. shtm>). Accessed: 14 mar 2008 (in Portuguese).
Maravalhas, N. 1964. Five studies of cassava flour. INPA, Manaus, AM, Brasil. 9 pp. (in Portuguese).

STATISTICA for Windows 5.5. 2000. Computer Program Manual. Tulsa: StatSoft, Inc.

Vilpoux, O. 2003. Culture of starchy tubers in Latin America. Volume 3: Technology, use and potentialities of Latin-American starchy tubers, Fundação Cargill, São Paulo, SP, Brasil. 694 pp (in Portuguese).

Recebido em 6/02/2010

Aceito em 26/11/2010 
